\title{
Study case ratio gear of stepper motor on electronic throttle using PID control
}

\author{
Ayu Sandra Dewi ${ }^{1}$, Zainal Arifin ${ }^{2}$, Adiyasa I.W., ${ }^{3,}$ \\ 1,2,3 Department of Automotive Engineering, Universitas Negeri Yogyakarta, Kampus Karangmalang, Yogyakarta, \\ 55281, Indonesia \\ E-mail: iwayanadiyasa@uny.ac.id * \\ * Corresponding Author
}

\begin{tabular}{|c|c|}
\hline ABSTRACT & ARTICLE INFO \\
\hline $\begin{array}{l}\text { The throttle is a component that determines the amount of airflow into the } \\
\text { combustion chamber. The latest in-vehicle technology makes it possible to } \\
\text { adjust the fly valve electronically. The electronic system adjusts the angle size } \\
\text { by comparing the predetermined setpoints. In research, electronic system } \\
\text { designs are based on existing models. The throttle model uses a stepper motor } \\
\text { drive. Electronic control using a microcontroller with proportional-integral- } \\
\text { derivative (PID) control. While the setpoint is based on a reference from the } \\
\text { throttle position sensor (TPS) sensor. The greater the throttle reference value, } \\
\text { the greater the angle opening of the butterfly valve. The results of this study } \\
\text { obtained a simulation model of electronic throttle control from gear ratios of } \\
1: 1,5: 1 \text {, and } 10: 1 \text { for conventional vehicles. }\end{array}$ & $\begin{array}{r}\text { Article history } \\
\text { Received: } \\
\text { 15 March } 2021 \\
\text { Revised: } \\
14 \text { April } 2021 \\
\text { Accepted: } \\
14 \text { April } 2021 \\
\\
\text { Keywords } \\
\text { Butterfly valve } \\
\text { Microcontroller } \\
\text { PI control } \\
\text { Stepper motor } \\
\text { Throttle }\end{array}$ \\
\hline $\begin{array}{l}\text { This is an open-access article under the CC-BY-SA license. } \\
\text { (c) (i) (O) }\end{array}$ & \\
\hline
\end{tabular}

\section{Introduction}

The use of digital technology to replace mechanical controls is felt for the newest types of vehicles. Most modern vehicles adopt an electronic-based control system to control the performance of the combustion engine. The electronic control system makes up for the lack of performance of the mechanical control system. One of the most dominant mechanical control systems is throttle control or often called throttle by wire (TbW). Where, throttle control systems that often use wire ropes are replaced by using electric motor drives such as DC motors, servo, solenoid, and stepper [1]-[4].

The throttle is the part of the engine that controls the amount of air that enters the combustion chamber. There is a butterfly valve that is used as a barrier to incoming air. The larger the butterfly valve rotation, the greater the amount of air that enters the combustion chamber. Of course, the condition of the butterfly valve rotation greatly affects the performance and efficiency of the combustion engine, especially in vehicles. Several works of literature review the efficiency of the application of TbW technology. The development of TbW using an electronic system is carried out by adjusting the butterfly valve rotation using a DC motor or 
solenoid. Controls carried out on a DC motor or solenoid in modern vehicles are integrated with an electronic control unit (ECU) [5].

Whereas in conventional vehicles, throttle control is not integrated into the ECU. So, it is necessary to develop a separate electronic throttle control with the ECU. In this paper, we will discuss the design of electronic throttle control (ETC) for conventional vehicles [6]. Some literature has developed many electronic control systems for adjusting the angle of throttle movement. The throttle setting uses an electronic system such as a microcontroller or a simulated control system.

\section{Theoretical of Throttle}

\subsection{Throttle Body}

Fig. 1 shows the throttle body integrated with the stepper motor.

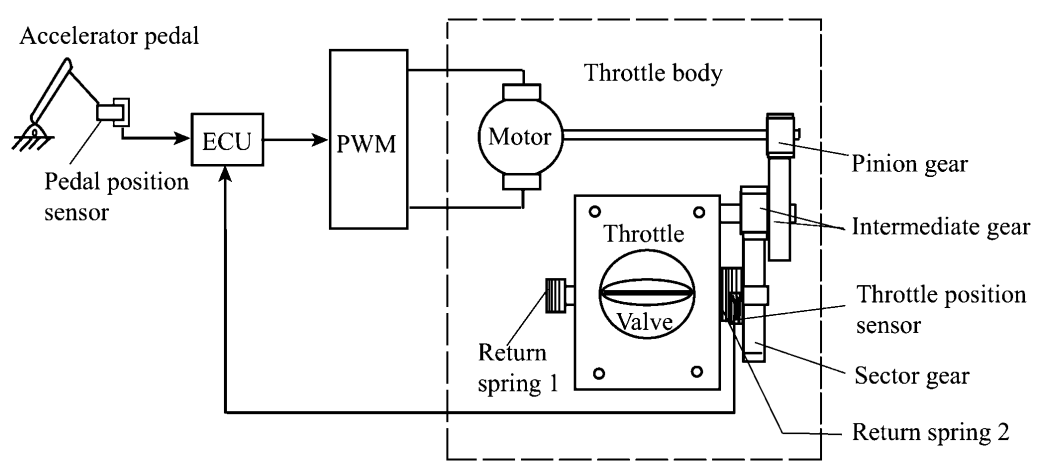

Fig. 1. Structure of TbW [7], [8]

The components contained in the TbW include sensors and actuators. The sensor that is often used is resistive, so the sensor output is a variation of the analog voltage from $0-5 \mathrm{~V}$. During the starting condition, the throttle sensor output voltage reaches 0V. Meanwhile, when the butterfly valve on the throttle is rotated, the output voltage on the throttle sensor changes and tends to increase [1], [5], [8]-[10].

The TbW drive in this paper uses a stepper motor. Where the stepper motor moves according to the pulse signal on the ETC. The amount of rotation between the butterfly valve and the stepper motor will use 3 conditions, namely the ratio 1: 1, 5: 1, and 10: 1 .

\subsection{Controlling of Stepper Motor}

The stepper motor is an actuator component that converts electrical energy into motion. The stepper motor movement can be regulated by regulating the electric current flowing to the stepper motor. Equations (1) and (2) show the maximum step time in 1 cycle of the ETC signal.

$$
\begin{aligned}
& a_{\max }=\frac{V}{2 L I_{\max } \times s p r} \\
& \min t / s t e p=\frac{2 L I_{\max }}{V}
\end{aligned}
$$

Where $a_{\max }$ is the maximum step, $\mathrm{V}$ is applied voltage, $I_{\max }$ is maximum current, $\mathrm{L}$ is stepper motor inductance, spr is step per revolution, mint/step is minimum time per step. Meanwhile, 
equation (3) shows the gear ratio between the stepper motor and butterfly valve on the throttle body.

$$
r_{\mathrm{t}}=\frac{\omega_{p}}{\omega_{s}}
$$

Where $r_{t}$ is gear ratio, $\omega_{p}$ is speed primary gear (stepper motor), $\omega_{s}$ is speed secondary gear (butterfly valve).

\subsection{PID Control}

Stepper motor control is carried out by various methods such as proportional-integralderivative (PID) control, fuzzy, linear control, and others [8], [11]-[13]. This paper focuses on the application of PID control to the control system to regulate the buttery valve rotation based on the orders from the ETC. Equation 4 shows the PID control function used in the ETC system.

$$
u_{p i d}=k_{p}\left(\theta_{r}-\theta\right)+k_{i} \int\left(\theta_{r}-\theta\right) d t+k_{d} \frac{d\left(\theta_{r}-\theta\right)}{d t}
$$

Where, $u_{\text {pid }}$ is the result of PID control, $k_{p}$ is a proportional constant value, $k_{i}$ is an integral constant value, $k_{d}$ is a derivative constant, $\theta_{r}$ is the previous angle value, $\theta$ is a readable angle value.

\section{Method}

There are 2 stages carried out in this research, namely designing the ETC simulation and case study.

\subsection{ETC Simulation Design}

Fig. 2 shows the simulation scheme in this paper. Where the pedal position sensor is indicated on the throttle. Where the throttle value is used as a reference value or setpoint. The setpoint value will be compared from the butterfly valve angle reading.

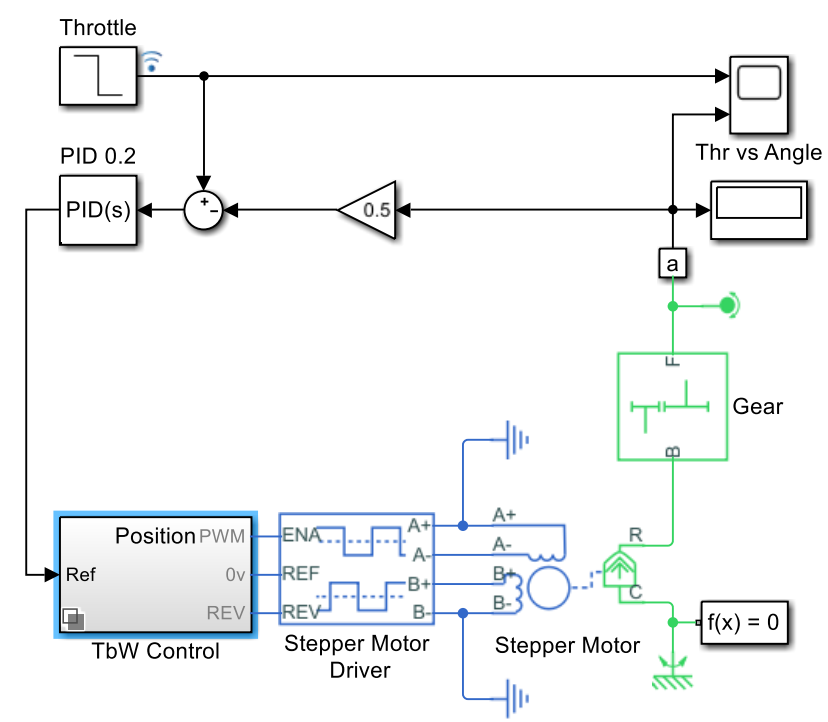

Fig. 2. ETC system simulation design

The difference between the setpoint and the reading result will be entered into the PID control system. Where each value has a different value for each gear ratio. This is because of the response and error generated for each ratio. 
Table 1. Constant values

\begin{tabular}{lll}
\hline Ratio Gear & Parameter & Value \\
\hline $1: 1$ & Proportional & 30 \\
& Integral & $1 \mathrm{e}-3$ \\
& Derivative & $5 \mathrm{e}-4$ \\
$1: 5$ & Proportional & 5.52 \\
& Integral & $1 \mathrm{e}-2$ \\
$1: 10$ & Derivative & $1 \mathrm{e}-4$ \\
& Proportional & 6.154 \\
& Integral & $5 \mathrm{e}-3$ \\
& Derivative & $25 \mathrm{e}-5$ \\
\hline
\end{tabular}

\subsection{Simulation Case Study}

The test is carried out in 3 cases, namely testing with a steady-state, and transient state. Each condition shows 3 gear ratio schemes.

\section{Results and Discussion}

\subsection{Steady State}

Tables 2 show the test result data. Where the test is carried out, changing the pedal position sensor gradually from an angle of 0 to 90 .

Table 2. Gear ratio

\begin{tabular}{cccccccccc}
\hline $\begin{array}{c}\text { Set } \\
\text { Point }\end{array}$ & \multicolumn{8}{c}{$\mathbf{1 : 1}$} & \multicolumn{7}{c}{$\mathbf{5 : 1}$} & $\mathbf{1 0 : 1}$ & \\
\cline { 2 - 10 } & Result & Deviation & $\begin{array}{c}\text { Error } \\
(\%)\end{array}$ & Result & Deviation & $\begin{array}{c}\text { Error } \\
(\%)\end{array}$ & Result & Deviation & $\begin{array}{c}\text { Error } \\
(\%)\end{array}$ \\
\hline 0 & 0.42 & 0.42 & 4.20 & -0.18 & -0.18 & 1.80 & -0.09 & -0.09 & 0.90 \\
5 & 4.99 & -0.01 & 0.20 & 4.86 & -0.14 & 2.80 & 4.95 & -0.05 & 1.00 \\
10 & 10.10 & 0.1 & 1.00 & 9.90 & -0.1 & 1.00 & 9.99 & -0.01 & 0.10 \\
15 & 13.98 & -1.02 & 6.80 & 14.94 & -0.06 & 0.40 & 14.85 & -0.15 & 1.00 \\
20 & 20.22 & 0.22 & 1.10 & 19.98 & -0.02 & 0.10 & 19.89 & -0.11 & 0.55 \\
25 & 24.25 & -0.75 & 3.00 & 25.02 & 0.02 & 0.08 & 24.93 & -0.07 & 0.28 \\
30 & 31.46 & 1.46 & 4.87 & 30.06 & 0.06 & 0.20 & 29.79 & -0.21 & 0.70 \\
35 & 34.62 & -0.38 & 1.09 & 35.10 & 0.1 & 0.29 & 34.83 & -0.17 & 0.49 \\
40 & 39.18 & -0.82 & 2.05 & 39.78 & -0.22 & 0.55 & 39.87 & -0.13 & 0.33 \\
45 & 42.88 & -2.12 & 4.71 & 44.82 & -0.18 & 0.40 & 44.91 & -0.09 & 0.20 \\
50 & 49.01 & -0.99 & 1.98 & 49.86 & -0.14 & 0.28 & 49.77 & -0.23 & 0.46 \\
55 & 53.58 & -1.42 & 2.58 & 54.90 & -0.1 & 0.18 & 54.81 & -0.19 & 0.35 \\
60 & 58.46 & -1.54 & 2.57 & 59.94 & -0.06 & 0.10 & 59.85 & -0.15 & 0.25 \\
65 & 63.70 & -1.3 & 2.00 & 64.98 & -0.02 & 0.03 & 64.89 & -0.11 & 0.17 \\
70 & 67.98 & -2.02 & 2.89 & 70.02 & 0.02 & 0.03 & 69.93 & -0.07 & 0.10 \\
75 & 74.22 & -0.78 & 1.04 & 75.05 & 0.05 & 0.07 & 74.79 & -0.21 & 0.28 \\
80 & 78.25 & -1.75 & 2.19 & 80.10 & 0.1 & 0.12 & 79.83 & -0.17 & 0.21 \\
85 & 85.46 & 0.46 & 0.54 & 84.78 & -0.22 & 0.26 & 84.87 & -0.13 & 0.15 \\
90 & 88.62 & -1.38 & 1.53 & 89.82 & -0.18 & 0.20 & 89.91 & -0.09 & 0.10 \\
& & Means error & 1.65 & & Means error & 0.20 & & Means error & 0.31 \\
\hline
\end{tabular}

Where, when using a gear ratio of 1: 1 shows a very large error with an average of $1.65 \%$. This can be due to the large difference between the setpoint and the reading of the butterfly valve rotation angle. The PID control change shows a very large value. The throttle sensor reading error is caused by a small gear ratio so that a 1 stepper motor causes a large angle change. 


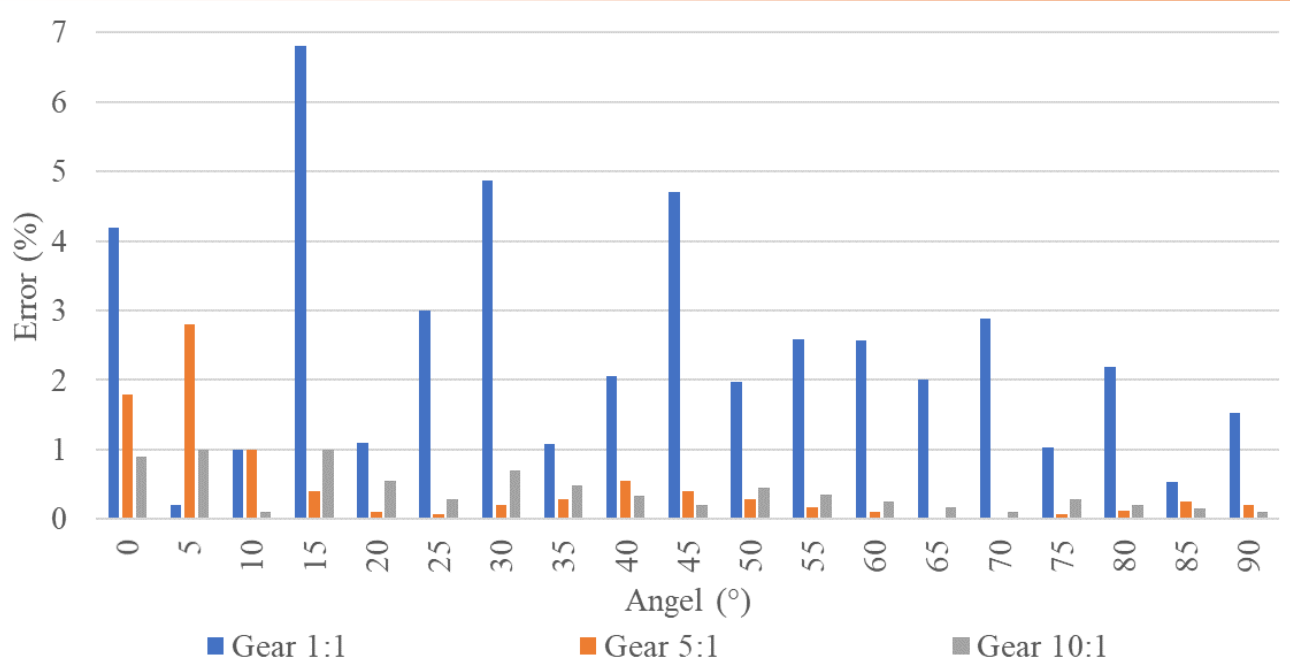

Fig. 3. Comparison of angle error in control

Whereas Tables 2 shows a fairly small error, namely $0.20 \%$ with a gear ratio of $5: 1$ and $0.31 \%$ with a gear ratio of $10: 1$. Of course, this is influenced by the rotary ratio between the stepper motor and the butterfly valve. Where there is an error when the gear ratio 1: 1 is greater than the gear ratio 5: 1 and 10: 1. In addition to the large rotational changes between the stepper motor and butterfly valve, the resolution of the sensor reader also affects the amount of error. The discussion regarding sensor reading resolution is not explained in this paper

\subsection{Study Case Transient}

Figures 4 to 6 show the control response on ETC. Where the attainment time between the setpoint and the reading on the gear ratio 1: 1 is faster than the gear ratio 5:1 and 10: 1 . This can be due to the many steps to reach the setpoint value.

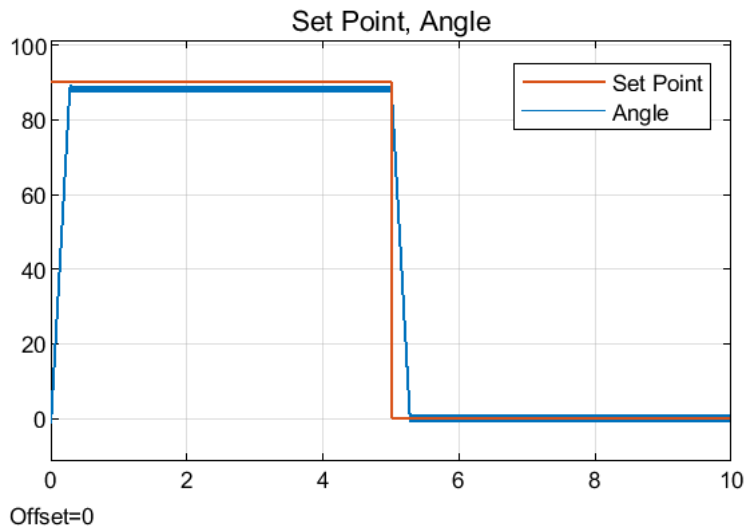

Fig. 4. The response of the throttle control at a 1:1 gear ratio

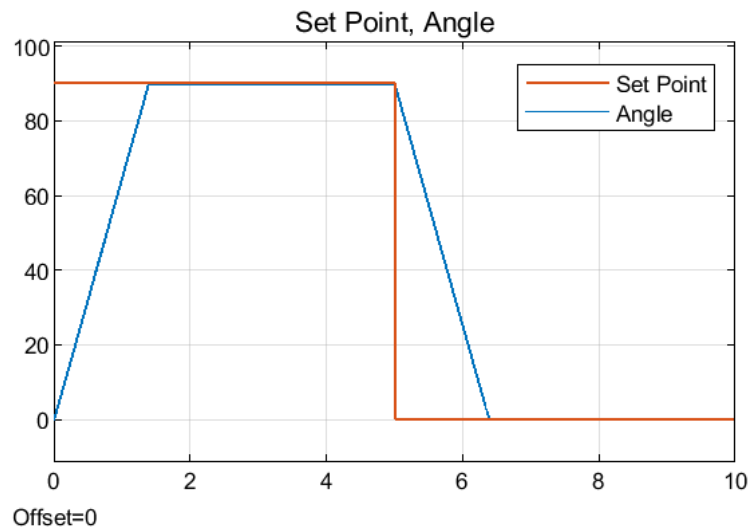

Fig. 5. The response of the throttle control at a 5:1 gear ratio 


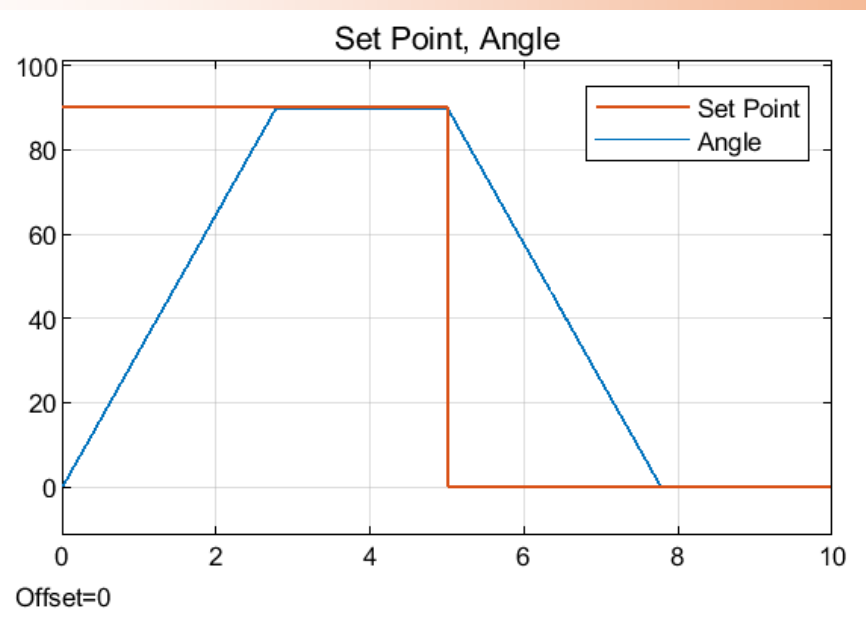

Fig. 6. The response of the throttle control at a 10:1

Table 5. Time Comparison

\begin{tabular}{ccc}
\hline Gear & Rise time (S) & Fall time (S) \\
\hline $1: 1$ & 3.089 & 3.089 \\
$5: 1$ & 15.444 & 15.444 \\
$10: 1$ & 30.889 & 30.889 \\
\hline
\end{tabular}

The greater the gear ratio, the longer the response time to reach the setpoint value. Table 3 shows the time it takes for the ETC and the stepper motor to reach its setpoint value. The test was carried out from a set point of $0^{\circ}$ to $90^{\circ}$, it can be seen that the rise time and fall time at the gear ratio of 1: 1 can reach a time of $3.089 \mathrm{~s}$, while the gear ratio of 5: 1 can reach $15.444 \mathrm{~s}$, and the gear ratio of 10: 1 can reach time 30,889s.

The longer the response it takes to reach the biggest corner, making ETC unresponsive. The unresponsiveness of ETC control causes the response of the combustion engine in a vehicle to be very slow. But ETC control with butterfly valve angle error also makes the combustion engine oscillate frequently.

\section{Conclusion}

Based on the simulation results by conducting 3 case studies, it was found that the use of a gear ratio with a response time of 1: 1 in reaching the setpoint was faster. Whereas the use of a 10: 1 gear ratio, the resulting output when the steady-state is more stable with small errors. The use of a gear ratio of 5: 1 in dynamic testing shows good results in terms of time and accuracy in reaching steady points.

\section{Acknowledgment}

The authors are grateful to the Automotive Engineering department and the Garuda UNY team who have supported the research and the success in its implementation.

\section{References}

[1] L. Gevorkov, V. Šmídl, and M. Sirový, "Stepper Motor Based Model of Electric Drive for Throttle Valve," Ann. DAAAM Proc. Int. DAAAM Symp., vol. 29, no. 1, pp. 1102-1107, 2018.

[2] R. P. Ruilope, "Modelling and Control of Stepper Motors for High Accuracy Positioning Systems Used in Radioactive Environments," Universidad Polit'ecnica de Madrid, 2014. 
[3] M. Reichhartinger and M. Horn, "Application of Higher Order Sliding-mode Concepts to a Throttle Actuator for Gasoline Engines," IEEE Trans. Ind. Electron., vol. 56, no. 9, pp. 3322-3329, 2009.

[4] X. Yuan, Y. Wang, and L. Wu, "SVM-based Approximate Model Control for Electronic Throttle Valve," IEEE Trans. Veh. Technol., vol. 57, no. 5, pp. 2747-2756, 2008.

[5] P. V. Kasab, N. B. Chopade, and S. Bhagat, "Implementation of Throttle Position Sensor for Angular Movement in Automobiles," Proc. - 2019 5th Int. Conf. Comput. Commun. Control Autom. ICCUBEA 2019, pp. 2-5, 2019.

[6] K. Song and S. Li, "Thermodynamic Characteristics Analysis of a High Temperature Fuel Flow-rate Control Valve," ISSCAA2010 - 3rd Int. Symp. Syst. Control Aeronaut. Astronaut., vol. 53, no. 3, pp. 1333-1338, 2010.

[7] J. Gao, K. Feng, Y. Wang, Y. Wu, and H. Chen, "Design, Implementation and Experimental Verification of A Compensator-Based Triple-Step Model Reference Controller For An Automotive Electronic Throttle," Control Eng. Pract., vol. 100, no. April, p. 104447, 2020.

[8] X. Jiao, J. Zhang, and T. Shen, "An Adaptive Servo Control Strategy for Automotive Electronic Throttle and Experimental Validation," IEEE Trans. Ind. Electron., vol. 61, no. 11, pp. 6275-6284, 2014.

[9] B. Ashok, S. Denis Ashok, and C. Ramesh Kumar, "Trends and Future Perspectives of Electronic Throttle Control System in a Spark Ignition Engine," Annu. Rev. Control, vol. 44, pp. 97-115, 2017.

[10]Y. Pan, Ü. Özguner, and O. H. Dağci, "Variable-Structure Control of Electronic Throttle Valve," IEEE Trans. Ind. Electron., vol. 55, no. 11, pp. 3899-3907, 2008.

[11]X. Jiao and T. Shen, PID Control with Adaptive Feedback Compensation for Electronic Throttle, vol. 45, no. 30. IFAC, 2012.

[12]Y. Li, B. Yang, T. Zheng, Y. Li, M. Cui, and S. Peeta, "Extended-State-Observer-Based Double-Loop Integral Sliding-Mode Control of Electronic Throttle Valve," IEEE Trans. Intell. Transp. Syst., vol. 16, no. 5, pp. 2501-2510, 2015.

[13] J. Xue, X. Jiao, and Z. Sun, "ESO-Based Double Closed-loop Servo Control for Automobile Electronic Throttle," IFAC-PapersOnLine, vol. 51, no. 31, pp. 979-983, 2018. 